\title{
Exploring the impact of built environment factors on the use of public bikes at bike stations: Case study in Zhongshan, China
}

\author{
Ying Zhang a,*, Tom Thomas ${ }^{\mathrm{b}}$, Mark Brussel ${ }^{\mathrm{a}}$, Martin van Maarseveen ${ }^{\mathrm{a}}$ \\ ${ }^{a}$ Faculty of Geo-Information Science and Earth Observation (ITC), University of Twente, PO Box 217, 7500AE Enschede, The Netherlands \\ ${ }^{\mathrm{b}}$ Centre for Transport Studies, University of Twente, PO Box 217, 7500AE Enschede, The Netherlands
}

\section{A R T I C L E I N F O}

\section{Article history:}

Received 25 January 2016

Received in revised form 30 September 2016

Accepted 24 November 2016

Available online $\mathrm{xxxx}$

\section{Keywords:}

Public bike systems

Trip data

Trip demand

Demand-supply ratio

Bike stations

Built environment factors

\begin{abstract}
A B S T R A C T
Many countries have implemented public bike systems to promote sustainable public transportation. Despite the rapid development of such systems, few studies have investigated how built environment factors affect the use of public bikes at station level using trip data, taking account of the spatial correlation between nearby stations. Built environment factors are strongly associated with travel demand and play an important role in the success of public bike systems. Using trip data from Zhongshan's public bike system, this paper employed a multiple linear regression model to examine the influence of built environment variables on trip demand as well as on the ratio of demand to supply $(\mathrm{D} / \mathrm{S})$ at bike stations. It also considered the spatial correlations of PBS usage between nearby stations, using the spatial weighted matrix. These built environment variables mainly refer to station attributes and accessibility, cycling infrastructure, public transport facilities, and land use characteristics. Generally, we found that both trip demand and the ratio of demand to supply at bike stations were positively influenced by population density, length of bike lanes and branch roads, and diverse land-use types near the station, and were negatively influenced by the distance to city center and the number of other nearby stations. However, public transport facilities do not show a significant impact on both demand and D/S at stations, which might be attributed to local modal split. We also found that the PBS usage at stations is positively associated with usage at nearby stations. Model results also suggest that adding a new station (with empty capacity) within a $300 \mathrm{~m}$ catchment of a station to share the capacity of the bike station can improve the demand-supply ratio at the station. Referring to both trip demand models and $\mathrm{D} / \mathrm{S}$ models, regression fits were quite strong with larger $\mathrm{R}^{2}$ for weekdays than for weekends and holidays, and for morning and evening peak hours than for off-peak hours. These quantitative analyses and findings can be beneficial to urban planners and operators to improve the demand and turnover of public bikes at bike stations, and to expand or build public bike systems in the future.
\end{abstract}

(c) 2016 Elsevier Ltd. All rights reserved.

\section{Introduction}

Public bike systems have become popular in many cities, in order to increase cycling, improve the accessibility of traditional public transport, and lessen the impact of motorized transport activities (Kaltenbrunner et al., 2010; Lin and Yang, 2011). Public bike programs provide public access to pick up and return bicycles at numerous fixed bike stations for free or against a small fee across an urban area. With these benefits and the improvement of operation and techniques on tracking public bikes, it has given birth to the rapid expansion of public bike programs throughout Europe, America, and Asia in recent years (Shaheen et al., 2010). Currently, there are more than 600 pubic bike programs across the world, of which around 162 are in China (ITDP-

\footnotetext{
* Corresponding author.

E-mail addresses: y.zhang-4@utwente.nl (Y. Zhang), t.thomas@utwente.nl (T. Thomas), m.j.g.brussel@utwente.nl (M. Brussel), m.f.a.m.vanmaarseveen@utwente.nl (M. van Maarseveen).
}

China, 2015). Some studies have shown that cycling has increased in cities after building public bike systems (Pucher et al., 2010).

Convenience and low travel cost have been perceived by users as major perceived benefits of public bike systems (Fishman et al., 2013). Public bike systems can not only offer rapid and flexible mobility for short distance trips, but also serve as a feeder mode for other public transport to improve the accessibility and reduce travel time of other public transport (Jäppinen et al., 2013). A public bike system mainly consists of numerous public bikes, fixed bike stations, and information service terminals. The success of public bike systems depends on how the users' demand for public bikes is satisfied (Frade and Ribeiro, 2014), and this highly depends on the location of bike stations (Bachand-Marleau et al., 2012). However, irrational locations and imbalanced capacity of bike stations have been reported as affecting the actual use of public bike systems (Liu et al., 2012; Vogel et al., 2011). This leads to a reduced demand of public bike systems. It is therefore important to know which (spatial) factors drive PBS demand, before planning the allocation of new PBS stations. 
Previous studies have shown that the bike-sharing ridership at station-level is associated with the surrounding built environment characteristics (Buck and Buehler, 2012; El-Assi et al., 2015; Ewing and Cervero, 2010; Faghih-Imani and Eluru, 2015, 2016; Faghih-Imani et al., 2014; Gonzalez et al., 2016; Maurer, 2012; Rixey, 2013; Wang et al., 2016), and with the kind of activities that take place in the neighborhood (Borgnat et al., 2011; Kaltenbrunner et al., 2010; Vogel et al., 2011). According to these studies, surrounding built environment characteristics mainly refer to population and job density, proximity to transit stations (metro and public bus stations) and bike lanes, and point of interests (retail shops, parks, restaurants, etc.) within the service area of each station. Moreover, station size, and number of bike stations within catchment area also have impact on the PBS demand at stations (El-Assi et al., 2015; Faghih-Imani and Eluru, 2015; Faghih-Imani et al., 2014). Most of aforementioned studies, except one from Faghih-Imani and Eluru (2016), employed traditional (nonspatial) regression analysis to examine the factors determining PBS demand, but did not consider spatial interaction between nearby stations. This may provide a distorted picture, as nearby stations may not be independent from each other. For example, users might shift from a station to nearby stations when the station is full or empty (Rudloff and Lackner, 2014).

The objective of this study is to understand how built environment factors affect the actual use of PBS. To this end, we examined the statistical relations between built environment variables and the actual use of public bikes at bike stations. Trip demand, i.e. the number of bikes picked up and dropped off at stations, and the demand to supply (supply being the number of parking slots) ratio were computed as two different indicators to represent the usage of public bikes at bike stations and were analyzed separately. We used spatial regression analysis to examine how surrounding built environment affects the system usage at stations, including the spatial interaction between nearby stations. The built environment factors - i.e. station attributes and accessibility, cycling infrastructure, public transport facilities, and land use characteristics within the potential service area of each station - are considered as explanatory variables. This quantitative analysis was done for a public bike system in Zhongshan which is a medium sized city in China, using trip database that includes the time and station location of pick-up and return of each trip from February to June 2014.

The rest of the paper is organized as follows. Section 2 gives a brief overview of relevant earlier studies, and in this context explains how this study was conducted. Section 3 introduces the study area, and presents the data screening. Section 4 describes the definition and generation of dependent and explanatory variables and model development. Section 5 presents results and discussion of the statistical models. Finally, Section 6 summarizes the paper.

\section{Literature review}

Many studies have stated that the mode choices are strongly associated with built environment characteristics in neighborhoods (Cervero et al., 2009; Ewing and Cervero, 2010; Kemperman and Timmermans, 2009; Moudon et al., 2005). Moreover, the impact of urban characteristics in neighborhood on mode choices is much stronger than the impact of subjective variables (personal perceptions) (Van Acker et al., 2013). A well-known measurement of built environment factors is " $D$ variables". The original three " $\mathrm{D}$ variables" - coined by Cervero and Kockelman (1997) - are density (population or job density), diversity (land-use mix), and design (street network characteristics), followed later by two additional variables - distance to transit, and destination accessibility (Ewing and Cervero, 2010). All these variables should be measured in a given area, i.e. neighborhood (Ewing and Cervero, 2010). Higher density, more diversity, and better accessible neighborhood (close to public transport, shops, leisure activities, etc.) (Ewing and Cervero, 2001; Van Acker et al., 2013), the proximity to bicycle- friendly infrastructure (e.g. bike lanes and trails) (Cervero et al., 2009; Heesch et al., 2015; Krizek and Johnson, 2006; Moudon et al., 2005) and transit stations (e.g. metro stations, and bus stops) (Cervero et al., 2009; Heesch et al., 2015) encourage more cycling. Moreover, street density and route connectivity are positively associated with utilitarian cycling (Cervero et al., 2009). It should be noted that the impact of built environment variables on cycling demand depends on various context variables, such as trip purpose (utilitarian, recreational), urban features (e.g. cities with and without uniformly compact neighborhoods) (Cervero et al., 2009; Heesch et al., 2015; Moudon et al., 2005). As a result, the relation between built environment variables and bicycle use can vary between different cities. For example, close to bicycle infrastructure and urban amenities (e.g. shops, CBD, etc.) there are key attributes influencing utilitarian cycling but not recreational cycling (Heesch et al., 2015). Most of the built environment factors (e.g. density, land-use diversity, accessibility to destination and transit stations) show a significant influence on cycling demand in developed countries but not in Bogota, which is attributed to the different urban features between cities of the developing and the developed world (Cervero et al., 2009).

As for public bike systems, there has been a growing attention towards understanding the effect of surrounding built environment characteristics on the bike-sharing ridership at station-level. The selection of built environment factors varies among different studies and these factors were usually analyzed in the catchment (buffer) area around each station. In general, some studies found that the population and job density, and the proximity to bike lanes, transit stations (public bus stops, metro stations) and points of interest (e.g. retail shops, restaurants, etc.), within a given area (service area) of each station are positively associated with ridership at stations (Buck and Buehler, 2012; Daddio, 2012; El-Assi et al., 2015; Faghih-Imani and Eluru, 2015, 2016; Faghih-Imani et al., 2014; Gonzalez et al., 2016; Nair et al., 2013; Wang et al., 2016). However, the effect of the built environment factors is not consistent across different studies. Rixey (2013) indicated that the positive effect of bike lanes only becomes significant when including the days with precipitation in the sample, and suggested that income levels and job types should be included when considering population density and job density. Moreover, Maurer (2012) found that population density and bike lanes have no significant relation with bike use. Additionally, several studies also found that station size (the capacity of station) and number of nearby bike stations have an impact on the ridership at stations, while the effects (positive or negative) are different among studies (El-Assi et al., 2015; Faghih-Imani and Eluru, 2015; Faghih-Imani et al., 2014). Furthermore, some studies indicated that severe weather conditions and calendar attributes (weekdays, weekends, and holidays) have influence on the system usage (Corcoran et al., 2014; Gebhart and Noland, 2014).

However, most of the aforementioned studies did not consider spatial correlations between nearby stations, which should actually be considered (Rudloff and Lackner, 2014). Also, most studies have not used distance-decay weighting of demographic or job variables within the service area, which could significantly influence the results (Gutiérrez et al., 2011). And finally, most studies were applied in western cities, whereas many new systems are developed in the developing world. In this study, we addressed some of these shortcomings. We used a spatial multiple linear regression model to examine the impact of built environment variables on trip demand as well as the ratio of demand to supply (D/S) at bike stations in a medium-sized Chinese city. China in particular is interesting, as many of the new PBS systems are launched in China. The selection of our built environment variables is based on the characteristics of public bike systems and the built environment factors (e.g. Density, Diversity, Design, Destination, and Distance) discussed by Ewing and Cervero (2010). In our study, spatial variables were analyzed within the catchment area of each bike station, and a distance decay function was used to compute population covered by each bike station. 


\section{Study area and data}

\subsection{Study area}

Zhongshan city is a prefecture-level city located in the Guangdong province of China, and directly opposite Hongkong (Fig. 1(A)). The city government directly administers 6 districts corresponding to the urban area, and 18 towns (Fig. 1(B)). Moreover, 4 districts, the Xi, Shiqi, Dong, and Nan districts, constitute the "center urban area" $\left(172.7 \mathrm{~km}^{2}\right)$, in which the Xi, Shiqi and Dong district are the political and cultural center of the city and are mainly occupied by the service industry and the Nan district holds the manufacturing and service industries. One of the other two districts, the Torch Hi-tech Industrial
Development district $\left(90 \mathrm{~km}^{2}\right)$, is a national-level hi-tech industrial development zone, and the Wuguishan district $\left(113 \mathrm{~km}^{2}\right)$ is mainly for tourism and agriculture. As shown in Fig. 1(C), the largest population is in the core of "center urban area", and less population in the Hi-tech and Wuguishan district. According to the statistics provided by the local transport planning department (before operating the PBS system), in the "center urban area", the non-motorized modes account for $46.3 \%$ of total trips, in which the share of bike trips is $18.9 \%$. The share of motorcycle and private car trips is $39.8 \%$ and $8.5 \%$ respectively, whereas $4.2 \%$ of trips are made by public bus. Referring to the travel time (distance) in the "center urban area", the average trip length is $2.7 \mathrm{~km}$, and $94.8 \%$ of total trips are less than $30 \mathrm{~min}$; moreover, the average length of walking trips is $0.8 \mathrm{~km}$, and the average length of cycling
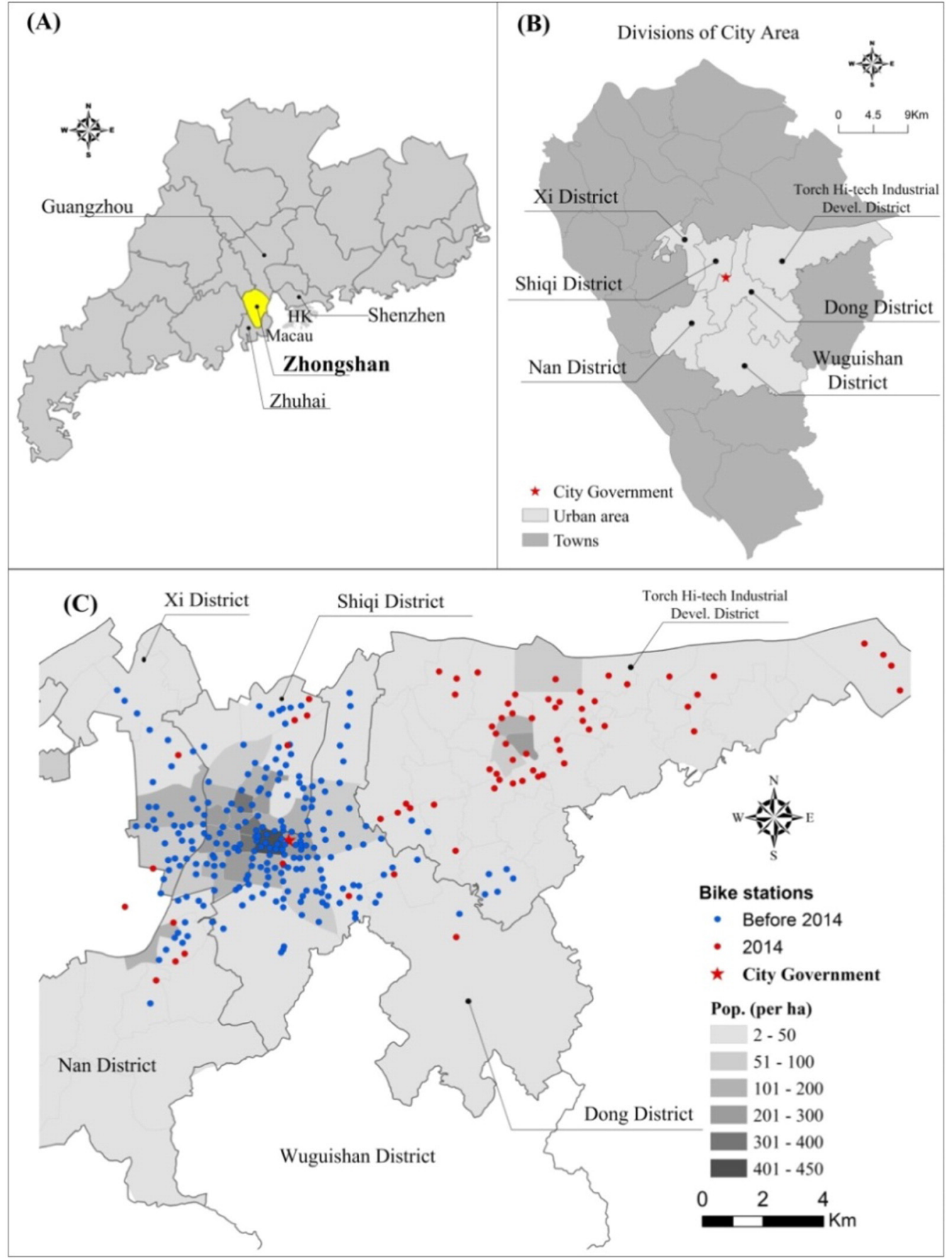

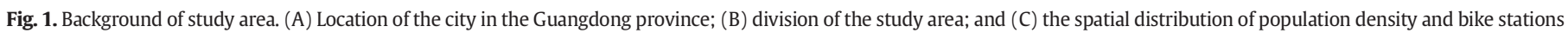
over the urban area. 
and public bus is $2.8 \mathrm{~km}$ and $4.8 \mathrm{~km}$ respectively. The statistics indicate that non-motorized modes (walking and cycling) and motorcycle are the main travel modes, the public bus, which is the only form of public transportation, is not attractive to residents, and the trip length and travel time of residents are quite short in this study area.

Zhongshan's public bike system was launched in 2011 and is a 24/7 self-service system. Users can pick up and return public bikes at any station in the course of day by use of a smart card after membership registration. For each trip, the first hour is free, and the rest of hours are charged at incremental price (1CNY per hour), which is quite a lot cheaper than a trip by local public bus (2 CNY per trip). The data were collected from the Transport Department of the Urban Planning and Design Institute of Zhongshan (China). The provided trip database consists of usage information from February to June 2014 ( 5 months). Each piece of usage information (i.e. each trip) includes user ID, bike ID, pickup and return stations, and start time and end time of the trip. Using the latter, the duration of each trip is calculated by subtracting the start time from the end time. According to the trip database, until June 2014, 296 bike stations, equipped with 7855 parking slots were distributed over the urban area; 224 of these stations had been built before 2014 and are mainly located in the "center urban area", and 72 bike stations were built in 2014 and are mainly located in "Torch Hi-tech Industrial Development district", as shown in Fig. 1(C). Additionally, the spatial database of the public bike system and urban attributes, such as population density, land use types, urban road network, and public transportation infrastructure, have also been provided by the local transport department.

\subsection{Data preparation}

Referring to the original trip database that records the usage of public bikes from February to June 2014, there are 1,937,265 records (i.e. trips), generated over the urban area in these 5 months. Based on data screening, we excluded $6 \%$ of inaccurate records from the original trip database, which included $5.88 \%$ of trips that had a pickup and return at the same station with a duration of less than $1 \mathrm{~min}$, and $0.12 \%$ of trips that had a duration of less than $1 \mathrm{~min}$. Moreover, the first two weeks of February 2014 contained Chinese New Year and Lantern Festival. Due to their special character and influence on activity patterns, we decided to exclude these two weeks from the analysis. Furthermore, we excluded newly-built bike stations (built in 2014), because they came on line during the measurement period. Although these newly-built stations were excluded from the regression analysis, they were used to validate the regression model to examine whether model results can also be applied to newly-built stations.

\section{Methodology}

\subsection{Selection and generation of dependent and explanatory variables}

We employed spatial multiple linear regression analysis to examine the statistical relations between built environment factors and trip demand at bike stations as well as the demand to supply ratio $(D / S)$ at bike stations. The daily demand at a station is given as the average amount of pickups and returns per day (Eq. (1)). The daily demand to supply ratio $(D / S)$ is equal to this average demand divided by the number of parking slots (supply) of the station (Eq. (2)). These were used to calculate the daily demand and daily $\mathrm{D} / \mathrm{S}$ at stations during weekdays, weekends, and holidays. Moreover, we also considered the demand within specific periods of weekdays, i.e. morning-peak (MP, 7:009:00), evening-peak (EP, 17:00-19:00), off-peak (the rest of the hours). The demand is calculated as the average hourly demand at each station (total demand per period divided by the number of hours). The trip demand and $\mathrm{D} / \mathrm{S}$ were used as dependent variable in different regression models. The descriptive statistics of daily and hourly demand and $\mathrm{D} / \mathrm{S}$ at stations are shown in Table 1 . Note that the number of pickups and returns at each of stations are in general quite comparable as might be expected.

Daily trip demand $=($ Pickups + Returns $) /$ Total days

Daily $\mathrm{D} / \mathrm{S}=$ Daily trip demand/Number of parking slots

In Table 1, the explanatory variables considered in this study are shown. These variables were selected based on the characteristics of public bike systems and built environmental factors as discussed by Ewing and Cervero (2010), such as land use diversity, destination accessibility, and distance to transit. Some spatial variables were computed within a buffer area. A buffer of a $300 \mathrm{~m}$ radius around each bike station was considered as an appropriate walking distance, as the distance between two nearby stations is often less than $300 \mathrm{~m}$ and the average trip length is around $10 \mathrm{~min}$. We refrained from using the catchment polygon around each bike station generated along the road network, because smaller roads are not complete in our dataset. Based on the complete road network, the calculation of service area using either Euclidean distance or network distance does not seem to decisively affect the results (Gutiérrez et al., 2011). By using a $300 \mathrm{~m}$ buffer around each station, spatial variables were computed at the same resolution for all stations.

The capacity of a station was used to examine the effect of station size (the number of parking slots) on the demand at the station. The number of other bike stations within $300 \mathrm{~m}$ buffer area was calculated to investigate the influence of nearby bike stations. The shortest network distance from a bike station to the location of the city government was calculated to examine the effect of the accessibility to the city center, as there is not a $\mathrm{CBD}$ to represent the main attraction point in center area. The size of the population within $300 \mathrm{~m}$ buffer area is expected to have a positive impact on the use of public bikes at bike stations, as potentially more people can use the system. The data of population is based on the census data that includes the size of the population in each TAZ (traffic analysis zone). The spatial distribution of population density in each TAZ has been shown in Fig. 1(C). The size of the population within the $300 \mathrm{~m}$ buffer area was computed using a distance decay function (proportional with the inverse of the distance), which means the further away users reside from a bike station the less likely they will use the bike station (Gutiérrez et al., 2011). Each buffer area was divided into six $50 \mathrm{~m}$ concentric rings. The propensity is constant within each ring and decays outwards, as is shown in Eq. (3), where $i$ equals the ID of each bike station, and $j$ represents each of the six rings. Additionally, it would be ideal to consider both population density and job density, distinguishing between income levels and job types. However, due to data limitation, we were unable to examine the impact of the variables relating to job density, income level, and job types. However, the spatial distribution of population to some extent can be an indication of human activities (e.g. job density) in study area, as jobs and housing are quite mixed in the study area, especially the central urban area with high density of stations.

$P D_{i}=\sum_{j=1}\left(P D_{i, j} / d_{j}\right)$

Cycling infrastructure variables refer to different levels of roads within the catchment area of each bike station in this study. We mainly considered bike lanes, major roads, secondary roads, and branch roads (the type of urban road is defined by MOHURD (2012)) within the catchment area of bike stations. The length of bike lanes within a 1000-m buffer was computed to identify whether bike lanes have a positive impact on demand at a bike station. We used larger buffer radius here as cycling trips are typically longer (1300 $\mathrm{m}$ on average for our sample) than walking distances, and are therefore more meaningful than a $300 \mathrm{~m}$ buffer radius when considering the safety in potential cycling areas (El-Assi et al., 2015). The length of major roads, secondary roads, and branch roads within a catchment area were calculated to 
Table 1

Descriptive statistics of explanatory variables and daily and hourly usage at stations.

\begin{tabular}{|c|c|c|c|c|c|c|}
\hline & & \multicolumn{3}{|l|}{ Description } & Mean & Std. Deviation \\
\hline \multicolumn{7}{|c|}{ Station attributes and accessibility } \\
\hline \multicolumn{2}{|l|}{ Capacity of the bike station } & \multicolumn{3}{|c|}{ Number of parking slots of a station } & 26.59 & 6.91 \\
\hline \multicolumn{2}{|c|}{ Number of other bike stations within $300 \mathrm{~m}$ buffer } & \multicolumn{3}{|c|}{ Number of other bike stations within a $300 \mathrm{~m}$ buffer of a station } & 1.13 & 1.28 \\
\hline \multicolumn{2}{|c|}{ Distance to city government (m) } & \multicolumn{3}{|c|}{ The shortest network distance from a station to city government } & 3340.02 & 1929.15 \\
\hline \multicolumn{2}{|c|}{ Population within $300 \mathrm{~m}$ buffer } & \multicolumn{3}{|c|}{ The size of population within $300 \mathrm{~m}$ buffer of a station based on the distance decay } & 16.32 & 15.91 \\
\hline \multicolumn{7}{|l|}{ Cycling infrastructure } \\
\hline \multicolumn{2}{|c|}{ Bike lane within $1000 \mathrm{~m}$ buffer (m) } & \multicolumn{3}{|c|}{ The length of bike lane within $1000 \mathrm{~m}$ buffer of a station } & 8702.95 & 4483.42 \\
\hline \multicolumn{2}{|c|}{ Main road within $300 \mathrm{~m}$ buffer (m) } & \multicolumn{3}{|c|}{ The length of main road within $300 \mathrm{~m}$ buffer of a station } & 563.51 & 362.50 \\
\hline \multicolumn{2}{|c|}{ Secondary road within 300 m buffer (m) } & \multicolumn{3}{|c|}{ The length of secondary road within $300 \mathrm{~m}$ buffer of a station } & 550.70 & 396.71 \\
\hline \multicolumn{2}{|c|}{ Branch road within $300 \mathrm{~m}$ buffer (m) } & \multicolumn{3}{|c|}{ The length of branch road within $300 \mathrm{~m}$ buffer of a station } & 1275.41 & 921.49 \\
\hline Public transport facilities & & & & & & \\
\hline Public bus stops within 300 & & Number of public $b$ & within $300 \mathrm{~m}$ bu & tion & 1.83 & 1.02 \\
\hline Distance to the closest publi & $(\mathrm{m})$ & The shortest netwo & from a station & est public bus stop & 165.47 & 166.01 \\
\hline Closest stop is a bus termina & & The closest public & a bus terminal & & 0.058 & 0.234 \\
\hline Closest stop is a transport hu & & The closest public & a transport hub & & 0.058 & 0.234 \\
\hline Land use characteristics & & & & & & \\
\hline Land use types within $300 \mathrm{n}$ & & Number of differen & types within 30 & of a station & 3.21 & 1.13 \\
\hline Near a shopping mall ( 0 or 1 & & The station located & shopping mall o & & 0.28 & 0.45 \\
\hline Near a residential communit & & The station located & residential comr & & 0.49 & 0.50 \\
\hline Near a recreational place $(0$ & & The station located & recreational plac & & 0.045 & 0.21 \\
\hline Near a park ( 0 or 1$)$ & & The station located & park or not & & 0.090 & 0.29 \\
\hline Daily and hourly usage at st & & & & & & \\
\hline & & Min & 25 percentiles & 50 percentiles & 75 percentiles & Max \\
\hline Daily demand at stations & Weekdays & 2.67 & 47.89 & 97.27 & 163.33 & 507.05 \\
\hline & Weekends & 2.36 & 41.52 & 78.64 & 136.21 & 475.85 \\
\hline & Holidays & 2.33 & 38.56 & 69.56 & 118.44 & 430.44 \\
\hline Hourly demand at stations & Morning-peak & 0.190 & 5.266 & 10.228 & 15.630 & 49.620 \\
\hline & Evening-peak & 0.190 & 5.516 & 10.918 & 16.625 & 63.652 \\
\hline & Off-peak & 0.059 & 1.301 & 2.864 & 4.832 & 15.314 \\
\hline Daily $\mathrm{D} / \mathrm{S}$ at stations & Weekdays & 0.09 & 1.94 & 3.83 & 6.52 & 16.32 \\
\hline & Weekends & 0.09 & 1.70 & 3.07 & 5.36 & 13.29 \\
\hline & Holidays & 0.11 & 0.38 & 0.99 & 1.57 & 11.24 \\
\hline Hourly D/S at stations & Morning-peak & 0.00614 & 0.199 & 0.429 & 0.631 & 1.654 \\
\hline & Evening-peak & 0.00614 & 0.209 & 0.418 & 0.689 & 2.122 \\
\hline & Off-peak & 0.00226 & 0.054 & 0.109 & 0.196 & 0.480 \\
\hline
\end{tabular}

understand the users' preference for routes (Faghih-Imani et al., 2014). In the urban area, major roads mainly connect each urban district, secondary roads contribute to distributing traffic to local areas, and branch roads mainly connect secondary roads and local communities and serve the traffic in local communities.

Public bikes are expected as a feeder mode for other public transport to improve the service of other public transport. The public bus system is the only traditional public transport in the study area. In order to know how public transport affects the demand and $\mathrm{D} / \mathrm{S}$ at bike stations, public transport variables considered in this analysis include the number of public stops within the catchment area, the shortest network distance to the nearest public bus stop, and the type of the nearest public bus stop. In the study area, public bus stops are classified in three types: normal stations, terminal stations, and transport hubs. The majority of public bus stops are normal stations. Transport hubs are located in the central area and have a larger potential demand, and terminal stations are mainly located in the remote area and have a lower demand.

Land use characteristics were calculated to capture the impact of land use diversity on the use of public bikes at bike stations. The influence of land use diversity on travel demand has been widely studied in transport studies (Ewing and Cervero, 2010). The number of different land use types within the $300 \mathrm{~m}$ buffer area was calculated to examine how the number of different land use types affects the demand at stations, although the study area has mixed land use patterns. Based on our data (spatial distribution of land use types over urban areas), i.e. the definition of land use types in study area, the land use types contain residential, commercial, educational, recreational, office, and industrial areas (which is mainly distributed on the periphery area and was excluded from calculation). We hypothesized that a higher number will lead to a higher demand, as different land use types might attract larger number of users with different travel purposes than a single land use type. For example, a station that covers both a shopping mall and a residential community can attract users that go for shopping, work in the shopping mall, or live there, but a station that covers a residential community can only attract users that live there or visit someone there. In the study area, different land use types are mixed in a street block and are divided into plots, the number of plots (with different land use types) within the $300 \mathrm{~m}$ buffer area is the number of land use types covered by a bike station. Moreover, we also considered the impact of dominant land use types - four attractions related to the land use type that is nearby each bike station: residential communities, shopping malls, recreational places, or parks. This was defined based on the principle of site-selection of bike stations in the study area: If a bike station is near (in front of the entrance of) a residential community, a shopping mall, a recreation place, or a park, then the bike station is named after the nearby residential community, shopping mall, recreational place, or park.

Finally, topography and weather are not considered in this study. Topography is not really an issue as there are no real height differences or other natural barriers that may discourage cycling. Weather conditions were considered as one of the potential factors that could have affected the use of public bikes, but only extreme weather conditions (pouring rain or blistering heat) really discourage cycling (Frade and Ribeiro, 2014). Zhongshan has a subtropical climate with an average temperature of $22{ }^{\circ} \mathrm{C}$ and no extreme temperatures between February and June. Rainfall was not extreme either and did not appear to have a significant influence on bicycle demand. According to the statistical correlation between daily rainfall and daily trips, the number of daily trips 
was not significantly $(\mathrm{p}<0.05)$ influenced by daily rainfall. We therefore did not consider weather conditions in the multiple linear regression analysis.

\subsection{Multiple linear regression models}

This section provides a brief description of the multiple linear regression model employed in this study. We firstly employed curve estimation analysis to examine whether the statistical relationship between dependent variable and each explanatory variable is linear or non-linear (e.g. logarithmic, power, exponential, etc.). The result of this analysis indicated that the data of the dependent variable and most of the explanatory variables should be transformed using the natural logarithm model (corresponding with a direct demand model), except for the data of distance to the city government and the categorical variables (see Table 1). This implies that the use of public bikes at a bike station goes down exponentially with the distance to the city government.

To explore the relationship between built environment variables and the PBS usage at stations, we used a spatial regression model with two spatially lagged variables, i.e. the spatially lagged dependent variable and the spatially lagged parking slots. Spatial correlation implies that the demand of one station is correlated with the demand of nearby stations, simply because they are in close proximity. Moreover, the demand of one station may also be associated the number of parking slots at neighboring stations. We therefore also included the spatially lagged parking slots as an extra spatial variable. By using these spatial variables, we are able to examine the spatial correlation between nearby stations and the spatial spillover effect. The spatial regression model is shown in Eq. (4).

$$
\begin{aligned}
\ln Y_{s}= & \beta_{0}+\beta^{\prime} X_{s[\text { Dis_Govt }]}+\sum \beta_{i} \ln X_{s i}+\sum \beta_{j} X_{s j}+\rho W \ln Y \\
& +\rho / W \ln X_{\text {slot }}
\end{aligned}
$$

where $s(=1,2,3, \ldots)$ is an index to represent each bike station, $\beta_{0}$ is a constant, $X_{s[\text { Dis_Govt }]}$ is the shortest network distance from station $s$ to the city government and $\beta^{\prime}$ is the corresponding model coefficient. $X_{s j}$ and $\beta_{j}$ are the categorical variables $(j)$ and their corresponding coefficients, and $X_{s i}$ and $\beta_{i}$ are the remaining independent variables $(i)$ and corresponding coefficients. The spatial weight matrix $\mathrm{W}$ has elements $w_{s s^{\prime}}$ expressing the potential spatial interaction between a station $s$ and the neighboring station $s^{\prime}$ in our study. $W \ln Y$ as the spatial lag dependent variable with spatial autoregressive parameter $\rho$, and $W \ln X_{\text {slot }}$ as spatially lagged parking slots with spatial autoregressive parameter $\rho^{\prime}$. W can be computed using contiguity rook and queen, inverse distance, $\mathrm{k}$ nearest neighbors, and so forth (Anselin and Rey, 2014). In our study, the observations are discrete points, which suits the inverse distance (with power 1) calculation within a threshold distance. We used $300 \mathrm{~m}$ as threshold distance to calculate the spatial weighted matrix $\mathrm{W}$. Moreover, a row-standardization transformation of $\mathrm{W}$ is adopted to make the estimation stable. All the spatial models were estimated by using maximum likelihood method in GeoDaSpace software (see Anselin and Rey (2014) for the explanation on software and approaches in detail).

We carried out the standard (non-spatial) multiple linear regression analysis using SPSS, and the spatial multiple regression analysis using GeoDaSpace. In order to have a good quality of output models, as suggested by Field (2009), we firstly ran the regression analysis in which all predictors were entered into the model, and examined the output to know which independent variables contribute significantly $(\mathrm{p}<0.05)$ to the model's ability to predict the outcome. Based on these important independent variables, we reran the multiple linear regression analysis using a Forward (stepwise) method that adds each significant $(\mathrm{p}<0.05)$ variable step by step, which was done by SPSS automatically and stopped when all the significant variables were included in the model. The analysis output displayed all the steps and the model generated in each step. Although the model generated in the final step has the largest $\mathrm{R}^{2}$ and contains all the significant variables, we still compared each model's result, including several statistics tables (e.g. Model summary, ANOVA, Coefficients, etc.) and standardized residual plots, to make sure that the final model had the best performance and had a significant fit to the overall data $(\mathrm{p}<0.05)$. The model estimates for weekdays, weekends, and holidays, as well as morningpeak, evening-peak, and off-peak were analyzed separately.

\section{Analysis and results}

\subsection{Model results}

In this section, we present and discuss the results of the multiple linear regression models. Note that we only show results that are statistically significant, i.e. those variables that contribute significantly to the dependent variable. The results are presented for demand in Table 2 (different days) and Table 4 (periods of the day), and for $\mathrm{D} / \mathrm{S}$ in Table 3 (different days) and Table 5 (periods of the day). The tables indicate that results are quite similar for demand and $\mathrm{D} / \mathrm{S}$, for different days, and for different periods of the day. The $\mathrm{R}^{2}$ value, and the magnitude (significance) and direction (positive or negative) of the coefficients are quite comparable, although regression fits appear to be somewhat better for the weekdays than for weekends and holidays, and also better for morning and evening peaks than for off-peaks. In the paragraphs, we elaborate on the influence of independent variables on demand and $\mathrm{D} / \mathrm{S}$.

Table 2

\begin{tabular}{|c|c|c|c|c|c|c|}
\hline \multirow[b]{2}{*}{$\operatorname{Ln}[\mathrm{D}]$} & \multicolumn{2}{|l|}{ Weekdays $^{\mathrm{a}}$} & \multicolumn{2}{|l|}{ Weekends ${ }^{\mathrm{b}}$} & \multicolumn{2}{|l|}{ Holidays $^{c}$} \\
\hline & Coefficient & t-Stat & Coefficient & t-Stat & Coefficient & t-Stat \\
\hline (Constant) & 2.621 & 6.525 & 0.441 & 0.701 & 0.068 & 0.106 \\
\hline Capacity of the station & - & - & $0.599^{* * *}$ & 4.150 & $0.674^{* * *}$ & 4.583 \\
\hline Number of other bike stations within $300 \mathrm{~m}$ buffer & $-0.582^{* * *}$ & -4.531 & $-0.459^{* * *}$ & -3.429 & $-0.490^{* * *}$ & -3.637 \\
\hline Number of population within 300 m buffer & $0.226^{* * *}$ & 5.325 & $0.223^{* * *}$ & 4.977 & $0.236^{* * *}$ & 5.175 \\
\hline Network distance to city government & $-0.000163^{* * *}$ & -4.834 & $-0.000127^{* * *}$ & -3.572 & $-0.000114^{* *}$ & -3.156 \\
\hline Length of bike lane within $1000 \mathrm{~m}$ buffer & $0.0727^{* *}$ & 3.279 & $0.0720^{* *}$ & 3.079 & $0.0608^{*}$ & 2.557 \\
\hline Length of branch road within $300 \mathrm{~m}$ buffer & $0.0826^{* * *}$ & 3.355 & $0.103^{* * *}$ & 3.955 & $0.101^{* *}$ & 3.836 \\
\hline Number of land use types within $300 \mathrm{~m}$ buffer & $0.544^{* * *}$ & 3.802 & $0.416^{* *}$ & 2.758 & $0.455^{*}$ & 2.961 \\
\hline Spatially lagged dependent variable & $0.1006^{* * *}$ & 3.358 & $0.0755^{*}$ & 2.329 & $0.0856^{*}$ & 2.564 \\
\hline
\end{tabular}

Regression coefficients for estimated models - dependent variable $\operatorname{Ln}[\mathrm{D}]$ of weekdays, weekends, and holidays.

a Model1 $\left(\mathrm{R}^{2}=0.697\right)$

b Model2 $\left(R^{2}=0.631\right)$.

c Model3 $\left(R^{2}=0.614\right)$.

*** $\mathrm{p}<0.001$.

** $\mathrm{p}<0.01$.

* $\mathrm{p}<0.05$. 
Table 3

Regression coefficients for estimated models - dependent variable Ln[D/S ] of weekdays, weekends, and holidays.

\begin{tabular}{|c|c|c|c|c|c|c|}
\hline \multirow[b]{2}{*}{$\operatorname{Ln}[\mathrm{D} / \mathrm{S}]$} & \multicolumn{2}{|l|}{ Weekdays $^{\mathrm{a}}$} & \multicolumn{2}{|l|}{ Weekends $^{\mathrm{b}}$} & \multicolumn{2}{|l|}{ Holidays $^{\mathrm{c}}$} \\
\hline & Coefficient & t-Stat & Coefficient & t-Stat & Coefficient & t-Stat \\
\hline (Constant) & 1.307 & 2.378 & -0.967 & -2.286 & -1.064 & -2.451 \\
\hline Capacity of the station & $-0.4023^{* *}$ & -3.011 & - & - & - & - \\
\hline Number of other bike stations within $300 \mathrm{~m}$ buffer & $-0.4016^{* * *}$ & -4.430 & $-0.302^{* *}$ & -3.209 & $-0.322^{* * *}$ & -3.445 \\
\hline Number of population within $300 \mathrm{~m}$ buffer & $0.213^{* * *}$ & 4.970 & $0.216^{* * *}$ & 4.713 & $0.218^{* * *}$ & 4.610 \\
\hline Network distance to city government & $-0.000185^{* * *}$ & -5.648 & $-0.000123^{* * *}$ & -3.438 & $-0.000105^{* *}$ & -2.869 \\
\hline Length of bike lane within $1000 \mathrm{~m}$ buffer & $0.0645^{* *}$ & 3.062 & $0.0687^{* *}$ & 2.911 & $0.0679^{* *}$ & 2.835 \\
\hline Length of branch road within $300 \mathrm{~m}$ buffer & - & - & $0.093^{* * *}$ & 3.562 & $0.101^{* * *}$ & 3.795 \\
\hline Number of land use types within $300 \mathrm{~m}$ buffer & $0.641^{* * *}$ & 4.663 & $0.501^{* * *}$ & 3.291 & $0.486^{* *}$ & 3.148 \\
\hline Near a park & $-0.316^{*}$ & -2.574 & - & - & - & - \\
\hline Near a residential community & - & - & $0.204^{* *}$ & 2.716 & - & - \\
\hline Spatially lagged dependent variable & $0.176^{* *}$ & 3.148 & $0.121^{*}$ & 1.955 & $0.153^{*}$ & 2.448 \\
\hline
\end{tabular}

a Model4 $\left(R^{2}=0.719\right)$.

b Model5 $\left(R^{2}=0.633\right)$.

c Model6 $\left(R^{2}=0.605\right)$.

*** $\mathrm{p}<0.001$.

** $\mathrm{p}<0.01$.

* $\mathrm{p}<0.05$.

As expected, bike stations with a higher demand and D/S are located in the center urban area with the highest population density (similar to findings of Daddio (2012)). The capacity of a bike station has a positive impact on the demand at the station on weekends and holidays (as well as the morning-peak and evening-peak of weekdays). This implies that the demand at a station is not significantly subject to the size of the station during off-peak hours of weekdays, but users prefer to choose the bike station with a larger capacity on weekends and holidays and during the morning-peak and evening-peak of weekdays (similar to the findings of El-Assi et al. (2015)), which might be attributed to the fact that choosing stations with larger capacity can increase the chance of finding an available slot or bike. Moreover, station capacity shows a negative impact on daily and hourly D/S at stations on weekdays (no influence on weekends and holiday, which is attributed to the $\mathrm{D} / \mathrm{S}$ calculation (Eq. (2)) - the magnitude of D/S (demand to supply ratio) varies inversely with station capacity.

The number of other bike stations within $300 \mathrm{~m}$ catchment area has a negative impact on both demand and $\mathrm{D} / \mathrm{S}$ at the bike station, i.e. the more other bike stations exist within $300 \mathrm{~m}$ catchment of a bike station, the lower the demand and $\mathrm{D} / \mathrm{S}$ generated at this station (same to the findings of daily customer model of Faghih-Imani and Eluru (2015)). This implies that potential competition exists between nearby bike stations. According to the $\mathrm{D} / \mathrm{S}$ model of weekdays, both station capacity and the number of other stations within $300 \mathrm{~m}$ catchment have negative impact, but the negative impact of station capacity is 1.7 times larger than the negative impact of number of other stations. When keeping other variables constant, we find that adding a new station (with empty capacity) within a $300 \mathrm{~m}$ buffer of a station to share the capacity of the bike station can improve the $\mathrm{D} / \mathrm{S}$ at the station, in other words, relocating the capacity of a station to a new station within $300 \mathrm{~m}$ buffer of the station.

Unsurprisingly, the use of public bikes at bike stations increases when there are more bike lanes built within $1000 \mathrm{~m}$ buffer area of these stations. The length of branch roads nearby a bike station also has a positive impact on the use of public bikes at the station, but the length of bigger roads (main road and secondary road) in the vicinity of a bike station has no statistically significant influence on the use of public bikes at the station (similar to the impact of minor roads indicated by Faghih-Imani et al. (2014)). Apparently, for these types of roads, the positive effect of accessibility is offset by the fact that these roads are not attractive for cyclists. In other words, these results imply that users prefer to cycle on bike-friendly roads and (branch) roads that are more accessible to local communities (e.g. residential, commercial, park, etc.) in the study area.

Table 4

Regression coefficients for estimated models - dependent variable Ln[D] of MP, EP, and off-peak.

\begin{tabular}{|c|c|c|c|c|c|c|}
\hline \multirow[b]{2}{*}{$\operatorname{Ln}[\mathrm{D}]$} & \multicolumn{2}{|l|}{ Morning-peak $^{\mathrm{a}}$} & \multicolumn{2}{|l|}{ Evening-peak $^{\mathrm{b}}$} & \multicolumn{2}{|l|}{ Off-peak ${ }^{c}$} \\
\hline & Coefficient & t-Stat & Coefficient & t-Stat & Coefficient & t-Stat \\
\hline (Constant) & -1.509 & -2.526 & -1.375 & -2.480 & -1.121 & -2.566 \\
\hline Capacity of the station & $0.555^{* * *}$ & 4.005 & $0.597^{* * *}$ & 4.645 & - & - \\
\hline Number of other bike stations within $300 \mathrm{~m}$ buffer & $-0.498^{* * *}$ & -4.542 & $-0.453^{* * *}$ & -4.331 & $-0.339^{* * *}$ & -3.648 \\
\hline Number of population within 300 m buffer & $0.131^{* *}$ & 2.974 & $0.184^{* * *}$ & 4.476 & $0.215^{* * *}$ & 4.492 \\
\hline Network distance to city government & $-0.000188^{* * *}$ & -5.498 & $-0.000171^{* * *}$ & -5.397 & $-0.000143^{* * *}$ & -3.855 \\
\hline Length of bike lane within $1000 \mathrm{~m}$ buffer & $0.106^{* * *}$ & 4.794 & $0.0833^{* *}$ & 4.048 & $0.0736^{* *}$ & 3.051 \\
\hline Length of branch road within $300 \mathrm{~m}$ buffer & $0.0765^{* *}$ & 3.097 & $0.0750^{* *}$ & 3.271 & $0.0915^{* * *}$ & 3.419 \\
\hline Number of land use types within $300 \mathrm{~m}$ buffer & $0.635^{* * *}$ & 4.421 & $0.531^{* * *}$ & 3.986 & $0.598^{* * *}$ & 3.852 \\
\hline Near a park & $-0.363^{* *}$ & -2.868 & $-0.433^{* * *}$ & -3.681 & - & - \\
\hline Spatially lagged dependent variable & $0.149^{* *}$ & 3.170 & $0.120^{* *}$ & 2.671 & $0.195^{* *}$ & 3.248 \\
\hline
\end{tabular}

a Model7 $\left(R^{2}=0.717\right)$.

b Model8 $\left(R^{2}=0.725\right)$.

c Model9 $\left(\mathrm{R}^{2}=0.671\right)$.

*** $\mathrm{p}<0.001$

** $\mathrm{p}<0.01$

$* \mathrm{p}<0.05$. 
Table 5

Regression coefficients for estimated models - dependent variable $\operatorname{Ln}[\mathrm{D} / \mathrm{S}]$ of MP, EP, and off-peak.

\begin{tabular}{|c|c|c|c|c|c|c|}
\hline \multirow[b]{2}{*}{$\operatorname{Ln}[\mathrm{D} / \mathrm{S}]$} & \multicolumn{2}{|l|}{ Morning-peak $^{\mathrm{a}}$} & \multicolumn{2}{|l|}{ Evening-peak ${ }^{\mathrm{b}}$} & \multicolumn{2}{|l|}{ Off-peak $^{\mathrm{c}}$} \\
\hline & Coefficient & t-Stat & Coefficient & t-Stat & Coefficient & t-Stat \\
\hline (Constant) & -1.527 & -2.529 & -1.435 & -2.567 & -3.070 & -4.867 \\
\hline Capacity of the station & $-0.443^{* *}$ & -3.183 & $-0.395^{* *}$ & -3.068 & $-0.391^{* *}$ & -2.695 \\
\hline Number of other bike stations within $300 \mathrm{~m}$ buffer & $-0.488^{* * *}$ & -3.649 & $-0.415^{* * *}$ & -3.349 & $-0.453^{* *}$ & -3.276 \\
\hline Number of population within 300 m buffer & $0.129^{* *}$ & 2.864 & $0.176^{* * *}$ & 4.160 & $0.2496^{* * * *}$ & 5.356 \\
\hline Network distance to city government & $-0.000187^{* * *}$ & -5.363 & $-0.000168^{* * *}$ & -5.185 & $-0.000154^{* * *}$ & -4.296 \\
\hline Length of bike lane within $1000 \mathrm{~m}$ buffer & $0.107^{* * *}$ & 4.729 & $0.0857^{* * *}$ & 4.087 & $0.0576^{*}$ & 2.424 \\
\hline Length of branch road within $300 \mathrm{~m}$ buffer & $0.0767^{* *}$ & 3.101 & $0.0754^{* * *}$ & 3.296 & $0.082^{* *}$ & 3.181 \\
\hline Number of land use types within $300 \mathrm{~m}$ buffer & $0.638^{* * *}$ & 4.423 & $0.543^{* * *}$ & 4.062 & $0.603^{* * *}$ & 4.006 \\
\hline Near a residential community & - & - & - & - & $0.204^{* *}$ & 2.696 \\
\hline Near a park & $-0.362^{* *}$ & -2.846 & $-0.425^{* * *}$ & -3.609 & - & - \\
\hline Spatially lagged dependent variable & $0.154^{*}$ & 2.506 & $0.143^{*}$ & 2.364 & $0.157^{*}$ & 2.562 \\
\hline Spatially lagged variable [Slot] & $0.147^{* *}$ & 2.926 & $0.112^{*}$ & 2.388 & $0.216^{* *}$ & 3.284 \\
\hline
\end{tabular}

a Model10 $\left(R^{2}=0.722\right)$.

b Model11 $\left(\mathrm{R}^{2}=0.730\right)$.

c Model12 $\left(\mathrm{R}^{2}=0.705\right)$.

*** $\mathrm{p}<0.001$.

** $\mathrm{p}<0.01$.

* $\mathrm{p}<0.05$.

The number of different land use types within the $300 \mathrm{~m}$ buffer of each station is associated with a positive impact on both demand and $\mathrm{D} / \mathrm{S}$ at bike stations. This implies that a higher demand and $\mathrm{D} / \mathrm{S}$ generated at stations in the vicinity of more diverse land use patterns. Stations near a residential community show a higher D/S during weekends and during the off-peak hours of weekdays, and stations near a park show a lower demand and D/S during morning-peak and evening-peak hours of weekdays. This indicates that residential stations have a larger turnover on weekends and during off-peak hours of weekdays, and stations near parks have a lower demand and turnover during morning-peak and evening-peak hours of weekdays.

The public transport variables did not have a statistically significant effect on the use of public bikes at bike stations. We have known that non-motorized modes and motorcycle are the main travel modes before operating a public bike system, whereas the public bus system is less attractive to residents. Given that the use of a public bike system is free of charge in the first hour, which is much cheaper than a trip by public bus, the majority of users can choose public bikes to complete their entire trips without the necessity for transferring from/to public bus, which is similar to the use of PBS in Zhuzhou city (a medium-sized Chinese city) (Zhang et al., 2015). This implies that the significant role of a public bike system is not an intuitive feeder mode to exiting public transport system in our study, but serves as a single mode for users to complete the entire trips, which might be attributed to the local modal split and the condition of exiting public transport systems.

The spatial correlations do exist between neighboring stations, i.e. the demand at one station is positively correlated with the demand at neighboring stations (similar to the findings of FaghihImani and Eluru (2016)). Both daily and hourly demand (and D/S) at a station are positively correlated with the demand (and D/S) from nearby stations. Moreover, the hourly D/S at a station during weekdays is also positively correlated with the number of parking slots from nearby stations. The positive correlation of demand (and $\mathrm{D} / \mathrm{S}$ ) between nearby stations might be attributed to the reason that nearby stations share the same built environment attributes that result in the high (or low) demand at these stations (Cervero et al., 2009). Another reason might be that, due to the spillover effect of demand from nearby stations. For example, a high demand generated at a station, i.e. near its capacity (no bike or parking slot), users have to shift from this station to a nearby station to seek for an available bike (or parking slot) (similar to the finding of Rudloff and Lackner (2014)).

\subsection{Model validation}

Fig. 2 displays the model results versus the observed values for demand and D/S at bike stations built before 2014 (blue symbol) and stations built in 2014 (red symbol). The latter ones are used to check the validity of the regression model. Fig. 2 indicates that the residuals appear to be somewhat larger for the red stations, but this may be attributed to the fact that these stations are located in the Hi-tech industrial district and serve fewer people. As a consequence, random variation due to limited sample sizes is stronger for these stations. There is however no evidence for systematic overestimation or underestimation by the model. In other words, the model also seems to be valid for the new stations (red symbols in Fig. 2).

For the blue stations (stations built before 2014) in Fig. 2, the regression fit also seems to be appropriate. No systematic effects are detected when the unstandardized residuals are plotted versus the independent variables (Fig. 3 as illustration for the weekdays model). Although model values are not exactly the same as observed values, there is no systematic overestimation or underestimation by the model. Residuals larger than 2 times the standard deviation are shown by the red (square) symbols in Fig. 3, while those smaller than 2 times the standard deviation are shown by blue (triangle) symbols. These so-called outliers mostly are the same stations in the different models. To understand the nature of these outliers, the spatial distribution of non-outliers and outliers are shown in Fig. 4, these outliers are mainly distributed on the outer layer of "center urban area". In regard to outliers (bike stations), several independent variables, which did not have a significant contribution in the model results, might have a decisive impact on the PBS use at these bike stations in reality. This results in the use of public bikes at bike stations being overestimated or underestimated by the models. For example, one station (outlier) was underestimated by the model due to the fact that the station is far from the center (e.g. fewer bike lanes, etc.), while the station is located nearby a shopping mall, which possibly leads to a higher demand for these stations than the model expected. Generally speaking, although regression models did not perfectly match all the observations, they still indicate the impact of influential factors and their contributions to increasing or decreasing the use of public bikes at bike stations. 

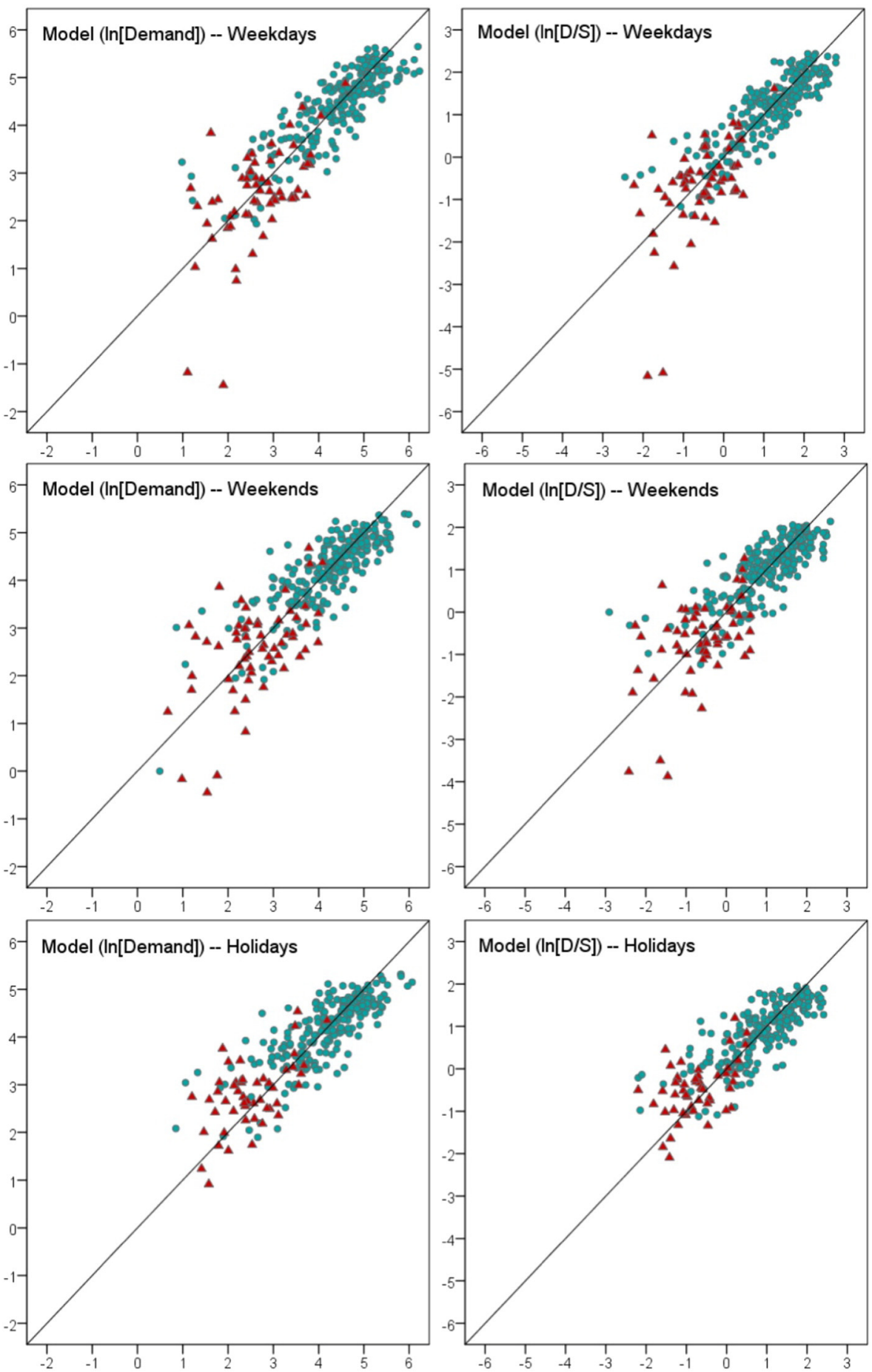

*(1) $X$ axis represents the observed value: In[Demand](left column), $\ln [\mathrm{D} / \mathrm{S}]$ (right column). $\mathrm{Y}$ axis represents the model value (2) Blue (circle symbol) stations were used for regression analysis, and red (triangle symbol) stations were used to validate model results.

Fig. 2. Predicted $(\mathrm{Y})$ versus observed $(\mathrm{X})$ values at each station. (For interpretation of the references to color in this figure, the reader is referred to the web version of this article.)

\section{Conclusions}

This study employed spatial multiple linear regression analysis to examine the impact of built environmental variables on trip demand as well as demand to supply ratio $(\mathrm{D} / \mathrm{S})$ at bike stations. We also considered the spatial spillover effect of nearby stations, i.e. the PBS usage (demand and $\mathrm{D} / \mathrm{S}$ ) and parking slots at nearby stations, using the spatial weighted matrix $\mathrm{W}$. The built environmental variables contain a range of factors relating to station attributes (station capacity, number of nearby stations), accessibility to city center and population density, cycling infrastructure, public transport variables, and land use characteristics surrounding the bike stations. Spatial variables were computed within the catchment area of each station, and a distance decay function was used to compute the size of population covered by each station. Trip data for Zhongshan's public bike system from February to June 2014 were gathered for carrying out the analysis. 

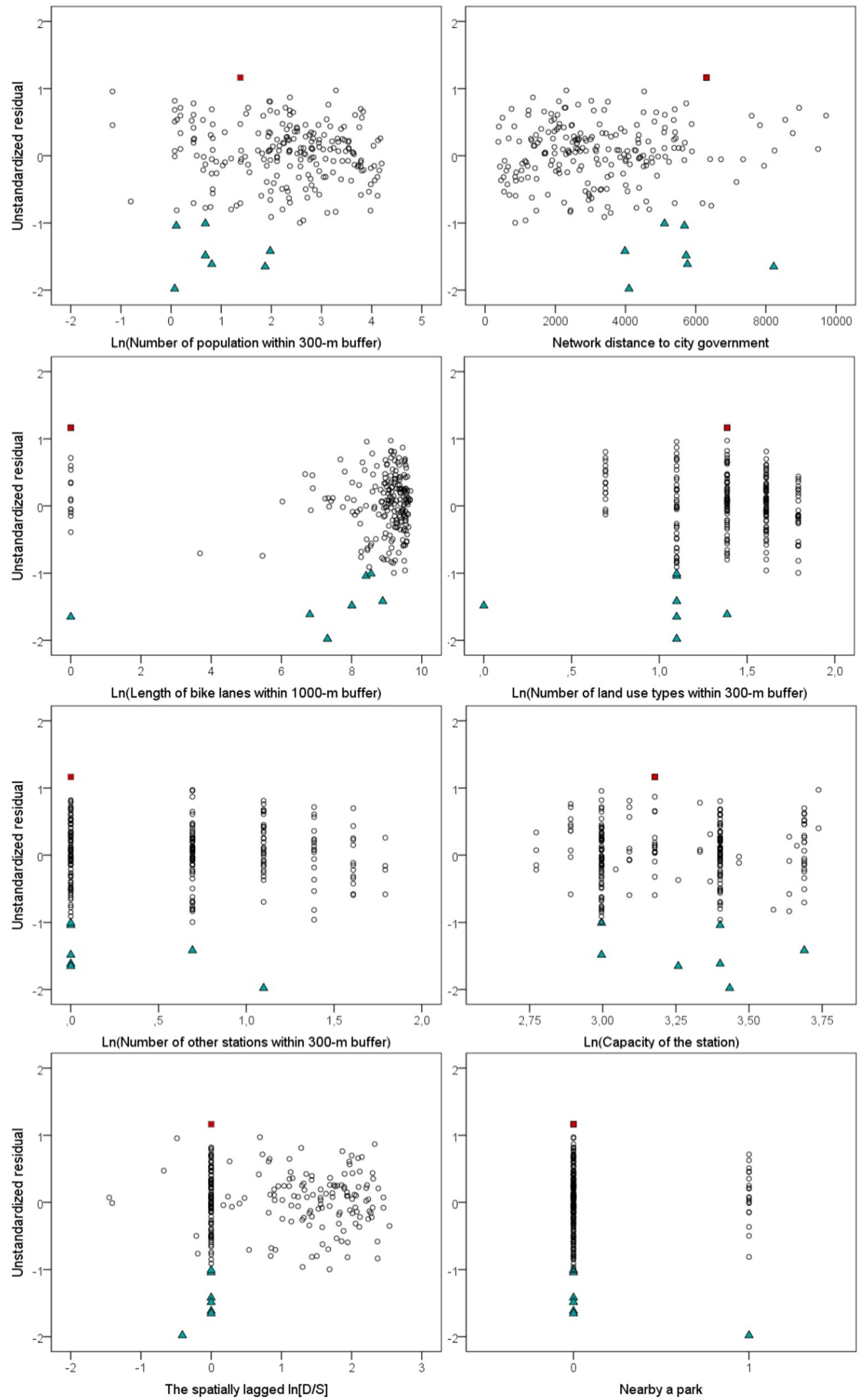

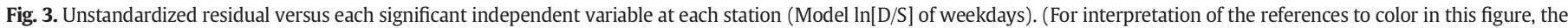
reader is referred to the web version of this article.)

Generally, we found that stations which are closer to the city center and have a higher population density within the $300 \mathrm{~m}$ buffer generated larger demands and $\mathrm{D} / \mathrm{S}$, which is a common findings (e.g. Daddio (2012)). As expected, users prefer to choose stations that cover more bike lanes and branch roads that offer a bike-friendly environment and are more accessible to local communities (same to the findings of Faghih-Imani et al. (2014)). Station capacity shows a positive impact on both daily and hourly demand at the station, implying that users 


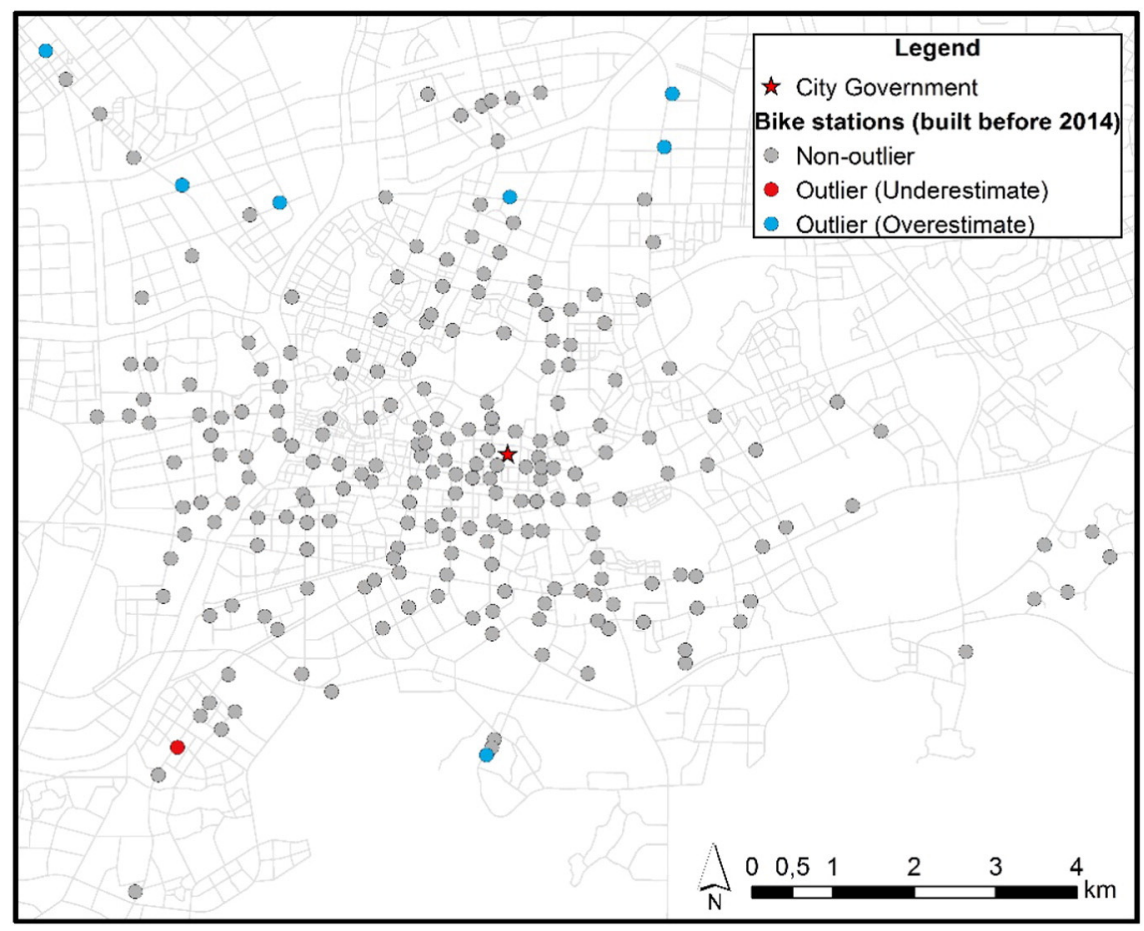

Fig. 4. Spatial distribution of outliers and non-outlier (bike stations).

show a preference for stations with a large capacity, in order to increase the chance of finding a bike or parking slot (El-Assi et al., 2015). Although the study area has mixed land use patterns, model results indicated that the larger the number of different land use types within the $300 \mathrm{~m}$ buffer, the larger demand (and $\mathrm{D} / \mathrm{S}$ ) generated at stations. This suggests that more diverse land use types might attract a larger number of users with different travel purposes than a single land use type. Moreover, a larger turnover generated at stations nearby a residential community during weekends and off-peak of weekdays, and lower turnover and demand generated at stations nearby a park during morning and evening peaks of weekdays.

There might be competition between nearby stations, i.e. users shift from a station to a nearby station to pick up or drop off bikes, as the number of other stations within the $300 \mathrm{~m}$ buffer of a station negatively affects both demand and $\mathrm{D} / \mathrm{S}$ at the bike station. Moreover, the spatially lagged dependent variable also indicated the spatial correlation of PBS usage between nearby stations, i.e. demand at a station is positively correlated with demand from nearby stations. This can be explained by two potential reasons: first, nearby station share the same built environment factors that result in the high (or low) demand at these stations (Cervero et al., 2009); second, the spillover effect of demand at nearby stations, i.e. if a station is near its capacity (no available bikes or parking slots), users will shift from a station to nearby stations to pick up or drop off bikes (Rudloff and Lackner, 2014).

The model of demand-supply ratio during weekdays indicated the negative impact of station capacity is 1.7 times larger than the negative impact of the number of other stations within the $300 \mathrm{~m}$ buffer. When keeping other variables constant, we found that adding a new station (with empty capacity) within a $300 \mathrm{~m}$ buffer of a current station to share the capacity of the current station can improve the $\mathrm{D} / \mathrm{S}$ at the current station, i.e. relocating the capacity of a station to a new station within the $300 \mathrm{~m}$ buffer of the station. This suggests that increasing the density of stations with small or medium-sized capacity can enhance the turnover at stations, which will also extend the service area of bike stations and reduce the travel distances.
In our study, the exiting public transport facility does not show a significant influence on the PBS usage at stations, implying that users did not tend to transfer from public bikes to public bus stops (or the other way round) in general, which is quite different from some other studies (e.g. Bachand-Marleau et al. (2012)). This can mainly be attributed to the local modal split and less attractive public bus system, as well as to the fact that the use of public bikes is free in the first hour, which is much cheaper than one trip on a public bus. This suggests that the significant role of the public bike system is not an intuitive feeder mode to exiting public transport system in our study, but serves as a single mode for users to complete the entire trips (similar to the usage of PBS in Zhuzhou city, a mediumsized Chinese city, indicated by Zhang et al. (2015)). Other studies also indicated that the role of public bike systems (e.g. feeder or replacement) varies in different Chinese cities, and public bike systems draw most of its users from unsheltered modes (walking, ebike, private bike, motorbike) (Campbell et al., 2016; Shaheen et al., 2011; Zhang et al., 2015). Moreover, even in large cities, such as Beijing, Hangzhou, with well-developed public transport systems, public bikes acted as both a supplement and a competitor to existing public transport systems (Campbell et al., 2016; Shaheen et al., 2011). Although the guideline on building public systems is quite the same all over the world at the present stage, there is a substantial necessity to understand the local travel modes before building public bike systems, and define the role of public bike systems in the context of cities rather than a priori treat such systems as a feeder mode to exiting public transport systems, so that the system can be used efficiently.

\section{Acknowledgements}

This work was supported by the China Scholarship Council (No. 2011627129) and co-funded by the ITC Research Fund (No. 93002823). We are grateful to the Transport Department of the Urban Planning and Design Institute of Zhongshan (China) for offering database and valuable help during fieldwork. We are also grateful for the 
valuable suggestions from the associate editor (Professor Becky Loo) and two anonymous reviewers.

\section{References}

Anselin, L., Rey, S.J., 2014. Modern Spatial Econometrics in Practice: A Guide to GeoDa, GeoDaSpace and PySAL. GeoDa Press, Chicago.

Bachand-Marleau, J., Lee, B., El-Geneidy, A., 2012. Better understanding of factors influencing likelihood of using shared bicycle systems and frequency of use. Transp. Res. Rec. 2314:66-71. http://dx.doi.org/10.3141/2314-09.

Borgnat, P., Abry, P., Flandrin, P., Robardet, C., Rouquier, J.B., Fleury, E., 2011. Shared bicycles in a city: a signal processing and data analysis perspective. Adv. Complex Syst. 14 (3):415-438. http://dx.doi.org/10.1142/s0219525911002950.

Buck, D., Buehler, R., 2012. Bike lanes and other determinants of capital bikeshare trips. Paper Presented at the Transportation Research Board 91st Annual Meeting, Washington DC . https://trid.trb.org/view.aspx?id=1130348.

Campbell, A.A., Cherry, C.R., Ryerson, M.S., Yang, X., 2016. Factors influencing the choice of shared bicycles and shared electric bikes in Beijing. Trans. Res. C: Emerg. Technol. 67: 399-414. http://dx.doi.org/10.1016/j.trc.2016.03.004.

Cervero, R., Kockelman, K., 1997. Travel demand and the 3Ds: density, diversity, and design. Transp. Res. Part D: Transp. Environ. 2 (3):199-219. http://dx.doi.org/10.1016/ S1361-9209(97)00009-6.

Cervero, R., Sarmiento, O.L., Jacoby, E., Gomez, L.F., Neiman, A., 2009. Influences of built environments on walking and cycling: lessons from Bogota. Int. J. Sustain. Transp. 3 (4):203-226. http://dx.doi.org/10.1080/15568310802178314.

Corcoran, J., Li, T., Rohde, D., Charles-Edwards, E., Mateo-Babiano, D., 2014. Spatio-temporal patterns of a Public Bicycle Sharing Program: the effect of weather and calendar events. J. Transp. Geogr. 41:292-305. http://dx.doi.org/10.1016/j.jtrangeo.2014.09.003.

Daddio, D.W., 2012. Maximizing Bicycle Sharing: An Empirical Analysis of Capital Bikeshare Usage. University of North Carolina at Chapel Hill.

El-Assi, W., Salah Mahmoud, M., Nurul Habib, K., 2015. Effects of built environment and weather on bike sharing demand: a station level analysis of commercial bike sharing in Toronto. Transportation:1-25 http://dx.doi.org/10.1007/s11116-015-9669-z.

Ewing, R., Cervero, R., 2001. Travel and the built environment: a synthesis. Transp. Res. Rec. (1780):87-114 http://dx.doi.org/10.3141/1780-10.

Ewing, R., Cervero, R., 2010. Travel and the built environment. J. Am. Plan. Assoc. 76 (3): 265-294. http://dx.doi.org/10.1080/01944361003766766.

Faghih-Imani, A., Eluru, N., 2015. Analysing bicycle-sharing system user destination choice preferences: Chicago's Divvy system. J. Transp. Geogr. 44:53-64. http://dx. doi.org/10.1016/j.jtrangeo.2015.03.005

Faghih-Imani, A., Eluru, N., 2016. Incorporating the impact of spatio-temporal interactions on bicycle sharing system demand: a case study of New York CitiBike system. J. Transp. Geogr. 54:218-227. http://dx.doi.org/10.1016/j.jtrangeo.2016.06.008.

Faghih-Imani, A., Eluru, N., El-Geneidy, A.M., Rabbat, M., Haq, U., 2014. How land-use and urban form impact bicycle flows: evidence from the bicycle-sharing system (BIXI) in Montreal. J. Transp. Geogr. 41:306-314. http://dx.doi.org/10.1016/j. jtrangeo.2014.01.013.

Field, A., 2009. Discovering Statistics Using SPSS. SAGE Publications Ltd., London.

Fishman, E., Washington, S., Haworth, N., 2013. Bike share: a synthesis of the literature. Transp. Rev. 33 (2):148-165. http://dx.doi.org/10.1080/01441647.2013.775612.

Frade, I., Ribeiro, A., 2014. Bicycle sharing systems demand. Procedia - Soc. Behav. Sci. 111:518-527. http://dx.doi.org/10.1016/j.sbspro.2014.01.085.

Gebhart, K., Noland, R.B., 2014. The impact of weather conditions on bikeshare trips in Washington, DC. Transportation 41 (6):1205-1225. http://dx.doi.org/10.1007/ s11116-014-9540-7.

Gonzalez, F., Melo-Riquelme, C., de Grange, L., 2016. A combined destination and route choice model for a bicycle sharing system. Transportation 43 (3):407-423. http:// dx.doi.org/10.1007/s11116-015-9581-6.

Gutiérrez, J., Cardozo, O.D., García-Palomares, J.C., 2011. Transit ridership forecasting at station level: an approach based on distance-decay weighted regression. J. Transp. Geogr. 19 (6):1081-1092. http://dx.doi.org/10.1016/j.jtrangeo.2011.05.004.
Heesch, K.C., Giles-Corti, B., Turrell, G., 2015. Cycling for transport and recreation: associations with the socio-economic, natural and built environment. Health Place 36 : 152-161. http://dx.doi.org/10.1016/j.healthplace.2015.10.004.

ITDP-China, 2015. China bikesharing. Retrieved from. http://www.publicbike.net/ defaulten.aspx.

Jäppinen, S., Toivonen, T., Salonen, M., 2013. Modelling the potential effect of shared bicycles on public transport travel times in Greater Helsinki: an open data approach. Appl. Geogr. 43:13-24. http://dx.doi.org/10.1016/j.apgeog.2013.05.010.

Kaltenbrunner, A., Meza, R., Grivolla, J., Codina, J., Banchs, R., 2010. Urban cycles and mobility patterns: exploring and predicting trends in a bicycle-based public transport system. Pervasive Mob. Comput. 6 (4):455-466. http://dx.doi.org/10.1016/j.pmcj. 2010.07.002.

Kemperman, A., Timmermans, H., 2009. Influences of built environment on walking and cycling by latent segments of aging population. Transp. Res. Rec. (2134):1-9 http:// dx.doi.org/10.3141/2134-01.

Krizek, K.J., Johnson, P.J., 2006. Proximity to trails and retail: effects on urban cycling and walking. J. Am. Plan. Assoc. 72 (1):33-42. http://dx.doi.org/10.1080/ 01944360608976722

Lin, J.-R., Yang, T.-H., 2011. Strategic design of public bicycle sharing systems with service level constraints. Trans. Res. E: Logist. Transp. Rev. 47 (2):284-294. http://dx.doi.org/ 10.1016/j.tre.2010.09.004.

Liu, Z., Jia, X., Cheng, W., 2012. Solving the last mile problem: ensure the success of public bicycle system in Beijing. Procedia - Soc. Behav. Sci. 43:73-78. http://dx.doi.org/10. 1016/j.sbspro.2012.04.079.

Maurer, L.K., 2012. Feasibility study for a bicycle sharing program in Sacramento, California. Paper Presented at the Transportation Research Board 91st Annual Meeting, Washington DC (https://trid.trb.org/view.aspx?id=1130876).

MOHURD, 2012. Code for Design of Urban Road Engineering. Ministry of Housing and Urban-Rural Development, China.

Moudon, A.V., Lee, C., Cheadle, A.D., Collier, C.W., Johnson, D., Schmid, T.L., Weather, R.D. 2005. Cycling and the built environment, a US perspective. Transp. Res. Part D: Transp. Environ. 10 (3):245-261. http://dx.doi.org/10.1016/j.trd.2005.04.001.

Nair, R., Miller-Hooks, E., Hampshire, R.C., Bušić, A., 2013. Large-scale vehicle sharing systems: analysis of Vélib. Int. J. Sustain. Transp. 7 (1):85-106. http://dx.doi.org/10. 1080/15568318.2012.660115.

Pucher, J., Dill, J., Handy, S., 2010. Infrastructure, programs, and policies to increase bicycling: an international review. Prev. Med. 50:S106-S125. http://dx.doi.org/10.1016/ j.ypmed.2009.07.028.

Rixey, R., 2013. Station-level forecasting of bikesharing ridership: station network effects in three U.S. systems. Transp. Res. Rec. (2387):46-55 http://dx.doi.org/10.3141/238706.

Rudloff, C., Lackner, B., 2014. Modeling demand for bikesharing systems neighboring stations as source for demand and reason for structural breaks. Transp. Res. Rec. (2430): 1-11 http://dx.doi.org/10.3141/2430-01.

Shaheen, S., Guzman, S., Zhang, H., 2010. Bikesharing in Europe, the Americas, and Asia past, present, and future. Transp. Res. Rec. (2143):159-167 http://dx.doi.org/10. 3141/2143-20.

Shaheen, S., Zhang, H., Martin, E., Guzman, S. (2011). Hangzhou public bicycle: understanding early adoption and behavioral response to bikesharing in Hangzhou China. (2247), 34-41. doi:10.3141/2247-05

Van Acker, V., Derudder, B., Witlox, F., 2013. Why people use their cars while the built environment imposes cycling. J. Transp. Land Use 6 (1):53-62. http://dx.doi.org/10. 5198/jtlu.v6i1.288

Vogel, P., Greiser, T., Mattfeld, D.C., 2011. Understanding bike-sharing systems using data mining: exploring activity patterns. Procedia - Soc. Behav. Sci. 20:514-523. http://dx. doi.org/10.1016/j.sbspro.2011.08.058.

Wang, X., Lindsey, G., Schoner, J.E., Harrison, A., 2016. Modeling bike share station activity: effects of nearby businesses and jobs on trips to and from stations. J. Urban Plann. Dev. 142 (1):04015001. http://dx.doi.org/10.1061/(ASCE)UP.1943-5444.0000273.

Zhang, L., Zhang, J., Duan, Z.-Y., Bryde, D., 2015. Sustainable bike-sharing systems: characteristics and commonalities across cases in urban China. J. Clean. Prod. 97:124-133. http://dx.doi.org/10.1016/j.jclepro.2014.04.006. 